\title{
Aspectos ecológicos da população de Culex quinquefasciatus Say (Diptera, Culicidae) em abrigos situados no Parque Ecológico do Tietê, São Paulo, SP
}

\author{
Gabriel Zorello Laporta ${ }^{1}$, Paulo Roberto Urbinatti ${ }^{1} \&$ Delsio Natal ${ }^{1}$
} 'Departamento de Epidemiologia, Faculdade de Saúde Pública, Universidade de São Paulo. Avenida Dr. Arnaldo, 715, Cerqueira César
01246-904 São Paulo-SP, Brasil. gabrielzorelo@usp.br

\begin{abstract}
Ecological aspects of Culex quinquefasciatus Say (Diptera, Culicidae) adult population in shelters at the Parque Ecológico do Tietê, São Paulo, SP. The study aimed to understand ecological aspects of Culex quinquefasciatus adult population in shelters along the year. Sampling of adults were carried out monthly during one year on a riverside vegetation. The insects were captured with a mechanical aspirator. Males and females were sorted and quantified; the degree of ovarian development was identified according to Sella's criterion. Meteorological data were correlated with the seasonal variations in the mosquito population. 8298 Cx. quinquefasciatus mosquitoes were collected. $6313(76 \%)$ were males and 1985 (24\%), females. 90,1\% of the females had an empty abdomen, 7,4\% had blood and 2,5\% had mature eggs. The correlation between number of mosquitoes versus temperature and rainfall was weak. The high proportion of males can be explained by female dispersal and by the tendency of males for staying in the shelters. It was observed that the riverside vegetation permits the accumulation of mosquitoes and represents a shelter for them.
\end{abstract}

KEYWORDS. Anthropic environment; epidemiology; public health; urbanization; vector.

RESUMO. Aspectos ecológicos da população de Culex quinquefasciatus Say (Diptera, Culicidae) em abrigos situados no Parque Ecológico do Tietê, São Paulo, SP. O estudo objetivou conhecer, ao longo das estações do ano, aspectos ecológicos da população adulta de Culex quinquefasciatus em abrigos. As coletas dos adultos foram realizadas mensalmente, cobrindo-se o período de um ano, na vegetação da margem de um canal de circunvalação. Os insetos foram capturados com o auxílio de um aspirador à bateria. O material foi acondicionado e transportado ao laboratório e, posteriormente, a espécie de interesse foi identificada; machos e fêmeas foram quantificados e o desenvolvimento ovariano foi identificado segundo o critério de Sella. Dados metereológicos foram coletados visando correlacioná-los com a variação sazonal da população de mosquitos. Foram coletados 8.298 mosquitos da espécie Culex quinquefasciatus. Desse total, 6.313 (76\%) eram machos e 1.985 (24\%) fêmeas. As fêmeas foram encontradas com o abdome vazio $(90,1 \%)$, com sangue $(7,4 \%)$ ou com óvulos maduros $(2,5 \%)$. As correlações de número de mosquitos coletados versus temperatura mensal média e precipitação mensal total não indicaram influência forte e positiva desses fatores na freqüência de mosquitos. A maior freqüência de machos pode ser explicada pela dispersão das fêmeas e pela permanência dos machos nos abrigos, representados pela vegetação na margem do canal favorecendo o acúmulo de mosquitos.

PALAVRAS-CHAVE: Ambiente antrópico; epidemiologia; saúde pública; urbanização; vetor.

As cidades se expandem carentes de saneamento, de saúde e de educação e contribuem, dessa forma, com o estabelecimento de condições favoráveis ao desenvolvimento de algumas espécies de mosquitos com importância em Saúde Pública.

Os Culicidae (Diptera) de interesse epidemiológico podem ser vetores de agentes infecciosos. Natal et al. (1991) referiram que Culex quinquefasciatus Say, 1823 é considerado, pela Saúde Pública, como fator de incômodo em inúmeras áreas urbanizadas do Brasil. De acordo com Forattini (2002), a presença dessa espécie, no ambiente urbano, é indesejável e constitui diminuição da qualidade de vida.

Estudos realizados na área periférica da grande São Paulo, no Parque Ecológico do Tietê (PET), mostram que, devido à disponibilidade de alimento, essa espécie é muito abundante. Nesse ambiente, há intensa proliferação dos imaturos em água estagnada com alta concentração de matéria orgânica (Taipelagos \& Natal 2003; Urbinatti et al. 2001). Aves silvestres, que representam fonte sangüínea para as fêmeas de mosquitos, estudadas por Pereira et al. (2001), no PET, eram numerosas, além da presença marcante do homem e de outros mamíferos. Salienta-se que, no local, os referidos autores detectaram o arbovírus Ilhéus, patogênico ao homem, em duas espécies de aves.

Devido à necessidade de investigações visando ampliar o conhecimento ecológico de Cx. quinquefasciatus, objetivouse estudar a freqüência, a distribuição por sexo, a variação sazonal, o desenvolvimento ovariano da população do mosquito e a associação entre essa e variáveis ambientais.

\section{MATERIAL E MÉTODOS}

Área de estudo. Escolheu-se o PET, estabelecido como Área de Proteção Ambiental (Lei 5.598, de 06 / 02 / 1987), que visa preservar a planície de inundação do rio Tietê de impactos decorrentes da urbanização e oferecer espaços de lazer à população. O Parque ocupa área verde de $140 \mathrm{~km}^{2}$, encravada no meio urbano, na divisa dos municípios de São Paulo - zona 
leste e de Guarulhos. Comporta vegetação reflorestada com espécies nativas de mata Atlântica, animais vertebrados residentes ou migradores, complexo de águas continentais formado por canais de circunvalação, lagos e pelo rio Tietê, além de equipamentos de lazer social (Ecotiete 2005).

Realizou-se o estudo na margem direita de um canal de circunvalação, conhecido como rio Negrinho, que está na divisa do PET com o bairro Jardim São Francisco, na várzea do rio Tietê. $\mathrm{O}$ canal recebe esgoto doméstico da área urbana adjacente e comporta ambiente eutrofizado onde ocorre intensa proliferação de imaturos de Cx. quinquefasciatus. Os habitantes, dessa área adjacente, são incomodados pelos mosquitos adultos (Urbinatti et al. 2001).

Metodologia. As coletas foram feitas em três pontos, dispostos em uma trilha de setecentos metros, denominados 1 (23K 343041, 7400206 UTM), 2 (23K 343389, 7400450 UTM) e 3 (23K 343450, 7400564 UTM), situados na margem direita do canal de circunvalação na qual se desenvolvem gramíneas (Poaceae) e mamoneiras (Euphorbiaceae) que servem de abrigos aos mosquitos. A vegetação, no local de captura, foi utilizada como complemento na caracterização do ambiente de repouso dos mosquitos e classificada como presente, retirada e em recuperação.

Foram realizadas coletas mensais, de setembro de 2003 a agosto de 2004, no período entre $10 \mathrm{~h}$ e $12 \mathrm{~h}$, utilizando-se aspirador à bateria durante 10 minutos em cada ponto .

Os mosquitos coletados foram mortos em clorofórmio, transferidos para caixas entomológicas e mantidos em recipiente de isopor com gelo reciclável. No laboratório o material foi identificado em estereomicroscópio e quantificado por sexo. De acordo com os estádios de Sella (1920), as fêmeas foram diferenciadas de três formas: vazias; com sangue e com óvulos maduros. Considerou-se que as fêmeas em estádios

Tabela I. Distribuição mensal percentual de Culex quinquefasciatus segundo o sexo, tipo de vegetação, temperatura e precipitação, de setembro de 2003 a agosto de 2004, no Parque Ecológico do Tietê, São Paulo, SP.

\begin{tabular}{|c|c|c|c|c|c|c|c|c|}
\hline \multirow{2}{*}{ Mês/Ano } & \multicolumn{2}{|c|}{ Macho } & \multicolumn{2}{|c|}{ Fêmea } & \multirow{2}{*}{$\begin{array}{c}\text { Total } \\
\mathrm{N}\end{array}$} & \multirow{2}{*}{ Vegetação } & \multirow[t]{2}{*}{$\mathrm{T}^{\circ} \mathrm{C}$} & \multirow[t]{2}{*}{$\mathrm{P}(\mathrm{mm})$} \\
\hline & $\mathrm{N}$ & $\%$ & $\mathrm{~N}$ & $\%$ & & & & \\
\hline Set/03 & 54 & 90 & 6 & 10 & 60 & $\mathrm{P}$ & 17,7 & 21,0 \\
\hline Out/03 & 375 & 82 & 79 & 18 & 454 & $\mathrm{P}$ & 19,5 & 122,0 \\
\hline Nov/03 & 644 & 79 & 168 & 21 & 812 & $\mathrm{P}$ & 20,4 & 147,0 \\
\hline Dez/03 & 443 & 80 & 112 & 20 & 555 & $\mathrm{P}$ & 21,7 & 129,0 \\
\hline $\mathrm{Jan} / 04$ & 1198 & 81 & 284 & 19 & 1482 & $\mathrm{P}$ & 20,8 & 183,0 \\
\hline $\mathrm{Fev} / 04$ & 192 & 69 & 87 & 31 & 279 & Ret & 20,7 & 214,0 \\
\hline Mar/04 & 53 & 72 & 21 & 28 & 74 & Rec & 20,3 & 96,0 \\
\hline $\mathrm{Abr} / 04$ & 749 & 78 & 207 & 22 & 956 & $\mathrm{P}$ & 20,6 & 48,0 \\
\hline Maio/04 & 883 & 79 & 237 & 21 & 1120 & $\mathrm{P}$ & 16,8 & 96,0 \\
\hline Jun/04 & 630 & 62 & 379 & 38 & 1009 & $\mathrm{P}$ & 15,9 & 43,0 \\
\hline Jul/04 & 540 & 70 & 230 & 30 & 770 & $\mathrm{P}$ & 15,4 & 50,0 \\
\hline Ago/04 & 552 & 76 & 175 & 24 & 727 & $\mathrm{P}$ & 16,6 & 1,0 \\
\hline Total & 6313 & 76 & 1985 & 24 & 8298 & & & $\overline{1150}$ \\
\hline
\end{tabular}

$\mathrm{N}=$ Número de mosquitos. $\%=$ Porcentagem de machos e de fêmeas pelo total de mosquitos. $\mathrm{T}^{\circ} \mathrm{C}=$ Temperatura mensal média. $\mathrm{P}(\mathrm{mm})=$ Precipitação mensal total. $\mathrm{P}=$ presente. Ret $=$ retirada. $\mathrm{Rec}=\mathrm{em}$ recuperação. de II a V continham sangue indicando desenvolvimento ovariano, em estádios VI e VII continham óvulos maduros e em estádio I eram vazias, sem desenvolvimento ovariano (Charlwood et al. 1980).

Os dados climáticos foram fornecidos pela Empresa Brasileira de Infra-estrutura Aeroportuária (INFRAERO), Guarulhos, SP. Os pontos de coleta foram referenciados geograficamente utilizando GPS (Global Positioning System) Carmin $^{\circledR}$.

Utilizou-se o índice de Pearson (Doria Filho 1999) para correlacionar o número de mosquitos versus a temperatura e a precipitação.

\section{RESULTADOS EDISCUSSÃO}

Foram coletados 8.298 adultos de $C x$. quinquefasciatus, sendo 6.313 (76\%), machos e 1.985 (24\%) fêmeas, com razão sexual de 3:1, em favor dos machos (Tabela I).

Possivelmente, o local de coleta, nas margens do criadouro com canal de água estagnada e matéria orgânica, abriga machos em predomínio, pois esses permanecem nas imediações e aguardam as fêmeas para a cópula. As fêmeas abandonam o abrigo e dispersam-se para os domicílios ou para o interior do Parque onde realizam o repasto sanguíneo. Esse comportamento de dispersão já foi constatado por Natal et al. (1991) à jusante, nas proximidades do rio Tietê. Schreiber et al. (1988) registraram a atividade hematofágica do $\mathrm{Cx}$. quinquefasciatus que se inicia a partir do crepúsculo vespertino.

Em fevereiro, parte da vegetação das margens do canal foi retirada e em março, estava em recuperação. $\mathrm{O}$ número de espécimes coletados diminuiu de 1.482 , em janeiro, para 279 e 74, em fevereiro e março, respectivamente e, em abril, após a recuperação da vegetação da margem do rio, observou-se aumento para 956 mosquitos coletados (Tabela I).

$\mathrm{O}$ número de espécimes de $C x$. quinquefasciatus variou em freqüência, no período estudado, na distribuição de machos e de fêmeas. A menor freqüência ocorreu em setembro, devido a problema técnico no aspirador que prejudicou a sucção. O acúmulo de mosquitos na vegetação da margem do canal foi verificado nas coletas de outubro a janeiro e de abril a julho (Tabela I). Assim como em Charlwood (1979), pequenas flutuações ocorreram nas amostras de mosquitos coletados durante o ano.

A retirada da vegetação, ocorrida ao longo do estudo no local de coleta, destruiu os abrigos e os mosquitos dispersaram-se para outras áreas. Admite-se que a redução dessa vegetação pode ter impelido os mosquitos para as áreas habitadas levando ao maior contato desses com a população. Reisen et al. $(1991,1992)$ estudaram a dispersão de $C x$. quinquefasciatus e recapturaram fêmeas, freqüentemente, nas áreas residenciais distantes $1,0 \mathrm{~km}$ do ponto de soltura.

A distribuição das fêmeas, nos três estados fisiológicos considerados foram: $1.788(90,1 \%)$ com o abdome vazio, 146 (7,4 \%) com sangue e 51 (2,5\%) com óvulos maduros (Fig. 1).

A presença de fêmeas ingurgitadas no abrigo demonstrou 
๑vazia - com sangue $₫$ com óvulos maduros

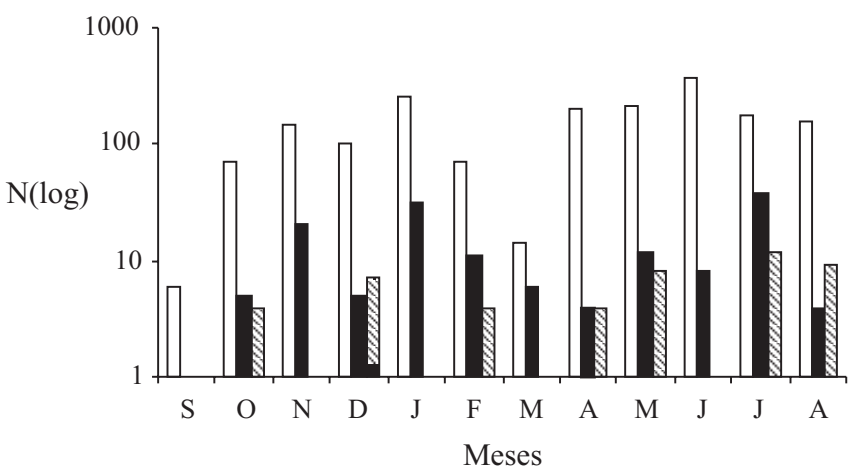

Fig. 1. Variação mensal do número de fêmeas de Culex quinquefasciatus quanto ao desenvolvimento ovariano, de setembro de 2003 a agosto de 2004, no Parque Ecológico do Tietê, São Paulo, SP. N (log) - Número de fêmeas em escala logarítmica.

que essas processam a digestão e a maturação dos folículos nesse local. A presença de fêmeas grávidas em repouso na vegetação ao longo das margens ocorreu, provavelmente, devido à proximidade do criadouro no qual ovipõem. Meillon et al. (1967) verificaram que a chegada de fêmeas grávidas no criadouro ocorre após o crepúsculo vespertino e durante o crepúsculo matutino. Sabendo-se que $C x$. quinquefasciatus é antropofílico (Charlwood 1979; Forattini et al. 1987; Samuel et al. 2004) as fêmeas ingurgitadas coletadas no local, possivelmente, teriam picado o homem que é um hospedeiro freqüente na área. $O$ contato com o homem na periferia urbana estudada eleva o potencial epidemiológico desse mosquito, o qual tem sido incriminado como potencial vetor do vírus da febre do Nilo Ocidental por Turell et al. (2001) e por Natal et al. (2004).

No estudo de correlação com as variáveis climáticas, o mês de setembro não foi utilizado no cálculo, assim como os meses de fevereiro e março, pois a vegetação foi retirada ou apresentava recuperação. O índice de correlação de Pearson foi de 0,25 para a precipitação mensal total e número mensal de mosquitos e de 0,02 para a temperatura mensal média e número mensal de mosquitos.

As chuvas influenciaram pouco na densidade da espécie nos abrigos. A temperatura não exerceu efeitos sobre a população de mosquitos concentrada nos abrigos. Strickman (1988) constatou que a falta de chuvas na estação quente apresentou correlação com o decréscimo da oviposição.

Agradecimentos. Ao biólogo Walter Ceretti pela ajuda nos trabalhos de campo, à Direção e funcionários do Parque Ecológico do Tietê pela colaboração na utilização das dependências do local e à FAPESP pelo auxílio financeiro (processo $\mathrm{n}^{\circ}$ 03/09473-7).
Charlwood, J. D. 1979. Estudos sobre a biologia e hábitos alimentares de Culex quinquefasciatus Say de Manaus, Amazonas, Brasil. Acta Amazonica 9: 271-278.

Charlwood, J. D; J. A. Rafael \& T. J. Wilkes. 1980. Métodos de determinar a idade fisiológica em Diptera de importância médica. Uma revisão com especial referência aos vetores de doenças na América do Sul. Acta Amazonica 10: 311-333.

Doria Filho, U. 1999. Introdução à bioestatística: para simples mortais. São Paulo, Negócio Editora, 152p.

Ecotiete. 2005. Histórico e projeto de criação do Parque Ecológico do Tietê. São Paulo. Disponível em: http://www.ecotiete.sites.uol. com.br. Acesso em: 01 fev. 2005.

Forattini, O. P.; A. C. Gomes; D. Natal; I. Kakitani \& D. Marucci. 1987. Preferências alimentares de mosquitos Culicidae no Vale do Ribeira, São Paulo, Brasil. Revista de Saúde Pública 21: 171-187.

Forattini, O. P. 2002. Espécie de Culex (Culex), p.693-722. In: O. P. Forattini. Culicidologia Médica - volume 2. São Paulo, Edusp, $860 \mathrm{p}$.

Meillon, B.; A. Sebastian \& Z. H. Khan. 1967. Time of arrival of gravid Culex pipiens fatigans at an oviposition site, the oviposition cycle and the relationship between time of feeding and time of oviposition. Bulletin World Health Organization 36: 39-46.

Natal, D.; C. H. Paganelli \& J. L. H. Santos. 1991. Composição da população adulta de Culex (Culex) quinquefasciatus Say, $1823 \mathrm{em}$ ecótopos próximos à represa Edgard de Souza, no município de Santana do Parnaíba, Estado de São Paulo, Brasil. Revista Brasileira de Entomologia 35: 539-543.

Natal, D.; F. A. A. Araújo; R. S. T. Vianna; L. E. Pereira \& H. M. Ueno. 2004. O mosquito das águas poluídas. Saneas: 26-31.

Pereira, L. E.; A. Suzuki ; T. L. M. Coimbra; R. P. Souza \& E. L. B. Chamelet. 2001. Arbovírus Ilhéus em aves silvestres (Sporophila caerulescens e Molothrus bonariensis). Revista de Saúde Pública 35: $119-123$.

Reisen, W. K.; M. M. Milby; R. P. Meyer; A. R. Pfuntner; J. Spoehel; J. E. Hazel rigg \& J. B. Webb Jr. 1991. Mark-release-recapture studies with Culex mosquitoes (Diptera: Culicidae) in southern California. Journal of Medical Entomology 28: 357-371.

Reisen, W. K.; M. M. Milby \& R. P. Meyer. 1992. Population dynamics of Culex mosquitoes (Diptera: Culicidae) along the Kern river, Kern county, California, in 1990. Journal of Medical Entomology 29: 531-543.

Samuel, P. P.; N. Arunachalam; J. Hiriyan; V. Thenmozhi; A. Gajanana \& K. Satyanarayana. 2004. Host-feeding pattern of Culex quinquefasciatus Say and Mansonia annulifera (Theobald) (Diptera: Culicidae), the major vector of filariasis in a rural area of south India. Journal of Medical Entomology 41: 442-446.

Sella, M. 1920. Relazione della campagna anti-anofelica di Flumicino (1919) con speciale riguardo alla biologia degli Anofelied agli Anofeli infetti. Annali da Igiene 30.

Schreiber, M. S.; M. S. Mulla; J. D. Chaney \& M. S. Dhillon. 1988. Dispersal of Culex quinquefasciatus from a dairy in southern California. Journal of the American Mosquito Control Association 4: 300-304.

Strickman, D. 1988. Rate of oviposition by Culex quinquefasciatus in San Antonio, Texas, during three years. Journal of the American Mosquito Control Association 4: 339-344.

Taipe-lagos, C. B. \& D. Natal. 2003. Abundância de culicídeos em área metropolitana preservada e suas implicações epidemiológicas. Revista de Saúde Pública 37: 275-279.

Turell, M. J.; M. R. Sardelis; D. J. Dohm \& M. L. O‘guim. 2001. Potential North American vectors of West Nile Virus. Annual New York Academy Sciense 951: 317-324.

Urbinatti, P. R.; S. Sendacz \& D. Natal. 2001. Imaturos de mosquitos (Diptera: Culicidae) em parque de área metropolitana aberto à visitação pública. Revista de Saúde Pública 35: 461-466. 